\title{
Comparison of WHOQOL-BREF and SF-36 in patients with HIV infection
}

\author{
Ping-Chuan Hsiung ${ }^{1}$, Chi-Tai Fang ${ }^{2,4}$, Yu-Yin Chang ${ }^{3}$, Mao-Yen Chen ${ }^{2}$ \& Jung-Der Wang ${ }^{2,3,4}$ \\ ${ }^{1}$ School of Nursing, College of Medicine, National Taiwan University; ${ }^{2}$ Department of Internal Medicine, \\ National Taiwan University Hospital; ${ }^{3}$ College of Public Health, National Taiwan University (E-mail: \\ jdwang@ha.mc.ntu.edu.tw); ${ }^{4}$ Garden of Mercy Foundation, Taiwan, ROC
}

Accepted in revised form 8 April 2004

\begin{abstract}
The purpose of the study was to evaluate the reliability and validity of the two generic instruments, the WHOQOL and the SF-36, for assessing health-related quality of life in 224 patients with HIV infection. The internal consistency ranged from 0.75 to 0.86 across the WHOQOL-BREF domains and from 0.72 to 0.93 across the SF-36 scales. The scores of all WHOQOL-BREF domains and SF-36 scales correlated positively with the measure of happiness, Sat-HRQOL and self-perceived health status, and correlated negatively with the number and intensity of symptoms. Patients with higher CD4 cell counts scored significantly higher on G4 (general health), three WHOQOL-BREF domains, seven SF-36 scales, and PCS (physical component summary). Patients with fewer symptoms and with less intensity of symptoms had significantly higher scores on all four domains of WHOQOL-BREF, eight scales, PCS, and MCS (mental component summary) of the SF-36 scale. The correlations between the physical, psychological, and social domains of the WHOQOL-BREF and PF (physical functioning), MH (mental health), and SF (social functioning) of the SF-36 were $0.51,0.75$, and 0.54 , respectively. There is also good correlation between PCS of the SF-36 and the physical domain of the WHOQOL-BREF $(r=0.48)$, and between MCS and all four domains of the WHOQOL-BREF ( $r$ range $=0.60-0.75$ ). The WHOQOL-BREF domains showed fewer floor or ceiling effect than the SF-36 scales. We concluded that both the WHOQOL-BREF and the SF-36 are reliable and valid health related quality-of-life instruments in patients with HIV infection.
\end{abstract}

Key words: HIV infections, Quality of life, SF-36, WHOQOL-BREF

\section{Introduction}

Effective treatment of patients with human immunodeficiency virus (HIV) with highly active antiretroviral therapy (HAART) has decreased morbidity and mortality in these patients [1]. Since April 1997, patients with HIV infection in Taiwan have been able to receive HAART subsidized by the National Health Insurance program. With effective pharmaceutical treatment, patients are able to strive for more fulfilling and meaningful lives.

As a result, in addition to focusing on disease outcomes, the personal and social well being of patients become crucial aspects in characterizing patient-centered outcomes. Quality of life (QOL) measures are one means to provide valuable information about patients both in clinical trials and for cost-effectiveness analysis for HIV disease [2-14]. Several QOL instruments have been applied in the evaluation of HIV-infected patients, including multiple versions of the Medical Outcome Study (MOS) [15-18], the Quality of Well-Being Scale [19], the HIV-QL31 [20], the HAT-QOL [21], the AIDS-HAQ [22], the HOPES [23], the MQoLHIV [24], the FAHI [25], and the World Health Organization Quality of Life Instrument (WHOQOL) [26]. Each questionnaire has its unique construct and advantages. The WHOQOL is a cross-cultural instrument developed for use across 
patient groups in various countries [27] and encompasses physical, psychological, social and environment domains [28]. However, the reliability and validity of the WHOQOL have not yet been compared with other instruments in HIV-infected patients. This study aimed at comparing the reliability and validity of the generic WHOQOLBREF [26, 29, 30] and the MOS Short Form-36 (SF-36) [18, 31-33], another well-established generic health-related QOL instrument that has been used with success in patients with HIV infection in various Asian countries.

\section{Methods}

Subject

After our pilot study consisting a sample of 136 HIV-infected patients [26] was completed, another 224 HIV-infected patients were recruited from the outpatient clinic of Taipei Municipal Venereal Disease Control Institute (VDCI), the inpatient unit of National Taiwan University Hospital (NTUH), and a mid-way shelter run by the Garden of Mercy Foundation (GMF). The VDCI and NTUH provide integrated and comprehensive therapy and services for the majority of patients with HIV infection in Taiwan. GMF is the leading non-governmental Christian organization dedicated to the welfare of people with HIV/AIDS in Taiwan. The diagnosis of HIV infection was confirmed by Western blot in all of the enrolled patients. Informed consent was obtained for all of the participants.

\section{Research instruments}

\section{The WHOQOL-BREF}

To facilitate cross-cultural comparison in QOL research, the World Health Organization initiated an international project to develop a generic QOL instrument resulting in the final version of the 100item WHOQOL long form. The 28-item WHOQOL-BREF Taiwan version [30] used in this study was a briefly summarized version of the WHOQOL-100. The 28 items include two general items (i.e. G1: overall QOL and G4: general health), 24 items universally adopted for WHOQOL-BREF to cover four domains (namely, physical, psycho- logical, social, and environment), plus two national items that were more specific for the culture of people of Taiwan (i.e. being respected/accepted among people, and eating what one loves to eat). The scores of the two general items range from 1 to 5 , with a higher score indicating a favorable condition. The domain scores range from 4 to 20 , and are calculated by multiplying the average scores for all items in the domain by 4 , with a higher score indicating a better QOL on the corresponding domain.

\section{The SF-36}

The SF-36 is a short-form health survey originally used in the MOS [31] in the United States. Subsequently, the International QOL Assessment (IQOLA) Project supported the feasibility of cross-cultural use of the SF-36 [34]. The SF-36 includes 36 items and covers eight scales: physical functioning (PF), role limitations due to physical health problems (RP), bodily pain (BP), general health perceptions (GH), vitality (VT), social functioning (SF), role limitations due to emotional problems (RE), and mental health (MH). All scales were linearly transformed to a 0-100 scale, with 0 indicating the least favorable status and 100 being the most favorable health status. The SF-36 also includes one item that measures health transition, which was excluded from scoring in this study. Two summary measures, the physical component summary (PCS) and the mental component summary (MCS), aggregate the 8 scales. Studies showed that three scales (PF, RP, BP) contribute most to the scoring of the PCS measure, and three scales (MH, RE, SF) contribute most to the scoring of the MCS measure $[35,36]$. Three of the scales (VT, GH, SF) have noteworthy correlations with both components. PCS and MCS were calculated using the data from the general Taiwan population [37].

\section{The measure of happiness}

The measure of happiness is a single item question using a five-point Likert scale, with a higher score indicating a favorable state.

\section{Sat-HRQOL}

Satisfaction with health-related quality of life (SatHRQOL) is a single item measure of overall sat- 
isfaction of health-related QOL. Scores range from 0 to 100 , with 0 indicating the least satisfactory and 100 being the most satisfactory health-related QOL.

\section{Health status measures}

Two health status measures were used to evaluate the validity of the selected QOL instruments. One is the self-perceived health status, a single item question using a five-point Likert scale with a higher score indicating a favorable state. The other is the revised Chinese version of the Sign and Symptom Check-List for Persons with HIV disease (SSC-HIV-CR) that measures number and intensity of HIV-related symptoms. This instrument consists the original 28 items from the SSCHIV-C [38, 39], plus two additional items, blurred vision and numbness, which were suggested by health care professionals experienced in providing HIV care. Item scoring for the SSC-HIV-CR ranges from 0 to 4 , with 0 indicating not having the corresponding symptom, 1 indicating the least symptom intensity, and 4 being the most intensity of the symptom.

The purpose of the study was to evaluate the reliability and validity of the two generic instruments, the WHOQOL and the SF-36, for assessing health-related QOL in patients with HIV infection. Specifically, the authors hypothesized that if both instruments accurately captured the health-related QOL of HIV-infected patients, then: (1) the corresponding domain/scale of both instruments should be positively correlated, i.e. the physical, psychological, and social domains of the WHOQOL-BREF should be significantly correlated with PF, MH, and SF scales of the SF-36, respectively; (2) the physical and psychological domains of the WHOQOL-BREF should have weak associations with MCS and PCS of the SF36, respectively; (3) the domain/scale scores of both instruments should be positively correlated with the measure of happiness, Sat-HRQOL, and self-perceived health status; (4) the domain/scale scores of both instruments should be inversely correlated with the number and intensity of symptoms; and (5) the domain/scale scores of both instruments could differentiate subjects with lower CD4 cell count, more symptoms and high intensity of symptoms from subjects with higher CD4 cell count, fewer symptoms and low intensity of symptoms.

\section{Statistical analysis}

Data were analyzed in the following aspects: (1) descriptive statistics, (2) tests of scaling assumptions (multitrait scaling methods), (3) reliability (Cronbach's $\alpha$ for internal consistency reliability), (4) content validity (correlations between item and its domain/scale and inter-domain/ scale correlations), (5) convergent and discriminant validity (correlations between scores of the two instruments), (6) concurrent validity (correlations between these two instruments with other measures), and (7) known-groups validity (Student's $t$ test, and analysis of variance). Data were computed using SPSS for Windows, Version 10.0 .

\section{Results}

\section{Characteristics of subjects}

Among the 224 enrolled patients, only one patient declined to participate. The majority of the participants were male $(96.0 \%)$ with high school education or above $(90.1 \%)$. Patients ranged in age from $21-75$ years (mean $=35$ years, standard deviation $=9.14$ years). Most of them $(91.1 \%)$ were receiving highly active antiretroviral therapy. The majority of the participants $(84.4 \%)$ had CD4 cell count above $200 / \mathrm{mm}^{3}$. A high percentage $(63.0 \%)$ of patients reported experiencing more than 10 symptoms. The characteristics of the 224 participants are summarized in Table 1.

Descriptive statistics for the WHOQOL-BREF and the $S F-36$

The score distributions of the WHOQOL-BREF and the SF-36 are summarized in Table 2. All of the WHOQOL-BREF domains and most of the SF-36 were negatively skewed, indicating distributions with more subjects scoring among the more favorable state. The full range of score distributions was exhibited for PF, RP, GH, SF, RE in the SF-36. All four domains of the WHOQOLBREF had trivial or no floor and ceiling effects. 
Table 1. Characteristics of 224 HIV-positive patients enrolled in this study

\begin{tabular}{ll}
\hline Characteristics & $\mathrm{n}=224(\%)$ \\
\hline Age (years) & \\
$\leqslant 30$ & $73(32.6)$ \\
$31-40$ & $108(48.2)$ \\
$>40$ & $43(19.2)$ \\
Male & $215(96.0)$ \\
Education of high school or above & $201(90.1)$ \\
Have been diagnosed with AIDS & $63(28.1)$ \\
Current antiretroviral therapy & $20(8.9)$ \\
None & \\
PIs or NNRTIs-based regimens ${ }^{\mathrm{b}}$ & $204(91.1)$ \\
Happiness & \\
Very unhappy & $16(7.1)$ \\
Unhappy & $48(21.4)$ \\
Moderately happy & $106(47.3)$ \\
Happy & $42(18.8)$ \\
Very happy & $11(4.9)$ \\
Self-perceived health status & $14(6.3)$ \\
Very poor & $47(21.3)$ \\
Poor & $93(42.1)$ \\
Fair & $52(23.5)$ \\
Good & $15(6.8)$ \\
Excellent & \\
Current CD4 cell count $\left(/ \mathrm{mm}^{3}\right)$ & $35(15.6)$ \\
$\leq 200$ & $93(41.5)$ \\
$201-500$ & $96(42.9)$ \\
$>500$ & $9(4.0)$ \\
Number of symptoms & $74(33.0)$ \\
None & $88(39.3)$ \\
$1-10$ & $53(23.7)$ \\
$11-20$ & \\
$21-30$ & \\
\hline
\end{tabular}

${ }^{a}$ Including treatment-naive new cases and patients under structured treatment interruption.

${ }^{\mathrm{b}}$ PIs: protease inhibitors; NNRTIs: non-nucleotide reverse transcriptase inhibitors.

Noteworthy flooring effects were observed for the two role-disability scales $(21.9 \%$ for RP and $25 \%$ for RE) in the SF-36 indicating problems with work or other activities as a result of physical health or emotional problems. Substantial ceiling effects were observed for two scales $(41.5 \%$ for PF, and $39.7 \%$ for BP) that indicate performing physical activities without limitations or with no pain. Substantial ceiling effects were also observed for the two role-disability scales $(48.7 \%$ for RP, and $50.9 \%$ for RE). Modest ceiling effects were observed for one scale $(18.8 \%$ for SF) that indicates performing social activities without interference.

\section{Tests of scaling assumptions}

Multitrait scaling techniques were used to evaluate item internal consistency and item discriminant validity (see Table 3 ). The range of the item internal consistency for the WHOQOL-BREF was $0.55-0.85$ and $0.64-0.96$ for the SF-36. A perfect success rate, with the criteria of correlations, which equal or exceed 0.40 , was observed in tests of the item internal consistency for both instruments. Results of item discriminant validity and scaling success rates are summarized in Table 3. A nearly perfect success rate was achieved in tests of the item discriminant validity for both instruments.

\section{Reliability}

The Cronbach's $\alpha$ values for internal consistency ranged from 0.75 to 0.86 across the domains of the WHOQOL-BREF, and from 0.72 to 0.93 across the scales of the SF-36 (see Table 2). All of the four WHOQOL-BREF domains and all of the 8 SF-36 scales had Cronbach's $\alpha$ values above 0.70 , which indicates that both instruments have good reliability.

\section{Validity}

Convergent and discriminant validity. Table 4 presents correlations for inter-domain/scale of the WHOQOL-BREF and the SF-36. The range of correlations for inter-domain/scale of the WHOQOL-BREF was 0.61-0.76 (all $p<0.0001$ ). It showed high associations among domains. All but two inter-scale correlations of the SF-36 were moderate to high associations ( $r$ range $=0.40$ 0.72 , all $p<0.0001)$. The exceptions were the associations between PF and $\mathrm{MH}(r=0.27)$ and between PF and VT $(r=0.37)$. Correlations between scores of the WHOQOL-BREF and the SF36 are also shown in Table 4. The relationships of the two general items, G1 (overall QOL) and G4 (general health) of WHOQOL-BREF showed weak to moderate associations with scales of the SF-36. The highest association $(r=0.64)$ was between G4 and GH of the SF-36. This implied that both measured similar concept. The weak associations were between the psychological, social and environment domains of the WHOQOL-BREF 
Table 2. Score distributions of the WHOQOL-BREF and the SF-36 $(\mathrm{n}=224)$

\begin{tabular}{|c|c|c|c|c|c|c|c|c|}
\hline & $\begin{array}{l}\text { Number of } \\
\text { items }\end{array}$ & Mean \pm SD & 25th percentile & Median & 75th percentile & $\begin{array}{l}\text { Percent scoring } \\
\text { at the floor }\end{array}$ & $\begin{array}{l}\text { Percent scoring } \\
\text { at the ceiling }\end{array}$ & Cronbach's $\alpha$ \\
\hline \multicolumn{9}{|c|}{ WHOQOL-BREF } \\
\hline Phy & 7 & $13.4 \pm 2.6$ & 12.0 & 13.2 & 14.9 & $0.4 \%$ & $0.0 \%$ & 0.79 \\
\hline Psy & 6 & $12.4 \pm 3$ & 10.0 & 12.7 & 14.7 & $0.0 \%$ & $0.0 \%$ & 0.85 \\
\hline Soc & 4 & $12.6 \pm 2.6$ & 11.0 & 13.0 & 14.0 & $0.4 \%$ & $0.0 \%$ & 0.75 \\
\hline Env & 9 & $12.7 \pm 2.5$ & 11.1 & 13.0 & 14.7 & $0.0 \%$ & $0.0 \%$ & 0.86 \\
\hline \multicolumn{9}{|l|}{$S F-36$} \\
\hline $\mathrm{PF}$ & 10 & $86.3 \pm 19.5$ & 80.0 & 95.0 & 100.0 & $0.4 \%$ & $41.5 \%$ & 0.93 \\
\hline $\mathrm{RP}$ & 4 & $63.3 \pm 41.4$ & 25.0 & 75.0 & 100.0 & $21.9 \%$ & $48.7 \%$ & 0.88 \\
\hline BP & 2 & $77.2 \pm 22.9$ & 62.0 & 80.0 & 100.0 & $0.0 \%$ & $39.7 \%$ & 0.89 \\
\hline GH & 5 & $53 \pm 23.2$ & 35.0 & 52.0 & 72.0 & $0.9 \%$ & $1.3 \%$ & 0.83 \\
\hline VT & 4 & $54 \pm 19.8$ & 40.0 & 55.0 & 70.0 & $0.0 \%$ & $1.3 \%$ & 0.82 \\
\hline SF & 2 & $70.8 \pm 22.4$ & 56.3 & 75.0 & 87.5 & $1.3 \%$ & $18.8 \%$ & 0.72 \\
\hline RE & 3 & $62.9 \pm 42.5$ & 16.7 & 100.0 & 100.0 & $25.0 \%$ & $50.9 \%$ & 0.85 \\
\hline MH & 5 & $57.6 \pm 18.9$ & 48.0 & 58.0 & 72.0 & $0.0 \%$ & $0.9 \%$ & 0.81 \\
\hline PCS & & $49.1 \pm 12.9$ & 42.2 & 53.0 & 58.4 & $0.0 \%$ & $0.0 \%$ & \\
\hline MCS & & $43.5 \pm 12.5$ & 35.1 & 43.2 & 52.5 & $0.0 \%$ & $0.0 \%$ & \\
\hline
\end{tabular}

Phy $=$ physical domain, Psy $=$ psychological domain, Soc $=$ social domain, Env $=$ environment domain, PF $=$ physical functioning, $\mathrm{RP}=$ role physical, $\mathrm{BP}=$ bodily pain, $\mathrm{GH}=$ general health perceptions, $\mathrm{VT}=$ vitality, $\mathrm{SF}=$ social functioning, $\mathrm{RE}=$ role emotional, $\mathrm{MH}=$ mental health, $\mathrm{PCS}=$ physical component summary, MCS $=$ mental component summary.

Table 3. Tests of item internal consistency and discriminant validity of the WHOQOL-BREF and the SF-36 ( $\mathrm{n}=224)$

\begin{tabular}{|c|c|c|c|c|c|c|}
\hline & \multicolumn{2}{|c|}{ Range of Correlations } & \multicolumn{2}{|c|}{ Internal Consistency Tests ${ }^{\mathrm{c}}$} & \multicolumn{2}{|c|}{ Discriminant Validity Test ${ }^{\mathrm{d}}$} \\
\hline & $\begin{array}{l}\text { Item-internal } \\
\text { consistency }^{\mathrm{a}}\end{array}$ & $\begin{array}{l}\text { Item-discriminant } \\
\text { validity }{ }^{\mathrm{b}}\end{array}$ & \#Success/total & Success rate $(\%)$ & \#Success/total & Success rate $(\%)$ \\
\hline \multicolumn{7}{|l|}{ WHOQOL-BREF } \\
\hline Physical & $0.55-0.79$ & $0.17-0.66$ & $7 / 7$ & 100 & $28 / 28$ & 100 \\
\hline Psychological & $0.65-0.85$ & $0.38-0.74$ & $6 / 6$ & 100 & $24 / 24$ & 100 \\
\hline Social & $0.70-0.82$ & $0.44-0.69$ & $4 / 4$ & 100 & $16 / 16$ & 100 \\
\hline Environmental & $0.58-0.74$ & $0.31-0.72$ & $9 / 9$ & 100 & $35 / 36$ & 97.2 \\
\hline \multicolumn{7}{|l|}{$S F-36$} \\
\hline $\begin{array}{l}\text { Physical } \\
\text { functioning }\end{array}$ & $0.64-0.86$ & $0.09-0.55$ & $10 / 10$ & 100 & $80 / 80$ & 100 \\
\hline Role physical & $0.84-0.88$ & $0.30-0.63$ & $4 / 4$ & 100 & $32 / 32$ & 100 \\
\hline Bodily pain & $0.95-0.96$ & $0.35-0.69$ & $2 / 2$ & 100 & $16 / 16$ & 100 \\
\hline $\begin{array}{l}\text { General health } \\
\text { perceptions }\end{array}$ & $0.72-0.83$ & $0.27-0.61$ & $5 / 5$ & 100 & $40 / 40$ & 100 \\
\hline Vitality & $0.75-0.86$ & $0.13-0.64$ & $4 / 4$ & 100 & $32 / 32$ & 100 \\
\hline Social functioning & $0.87-0.90$ & $0.35-0.61$ & $2 / 2$ & 100 & $16 / 16$ & 100 \\
\hline Role emotional & $0.85-0.90$ & $0.34-0.68$ & $3 / 3$ & 100 & $24 / 24$ & 100 \\
\hline Mental health & $0.65-0.84$ & $0.09-0.66$ & $5 / 5$ & 100 & $40 / 40$ & 100 \\
\hline
\end{tabular}

${ }^{\mathrm{a} C}$ Correlation between items and hypothesized scale corrected for overlap.

${ }^{\mathrm{b}}$ Correlations between items and other scales.

${ }^{\mathrm{c}}$ Number $\geqslant 0.40$.

${ }^{\mathrm{d}}$ Number of correlations significantly higher/total number of correlations.

with the PF of the SF-36 $(r$ range $=0.32-0.35)$. The associations between the psychological and social domains of the WHOQOL-BREF with the BP of the SF-36 $(r=0.33-0.39)$ were weak as well. The rest of the WHOQOL-BREF domains and the SF36 scales showed a moderate to substantial asso- 
Table 4. Correlation coefficients between WHOQOL-BREF and SF-36 $(\mathrm{n}=224)$

\begin{tabular}{|c|c|c|c|c|c|c|c|c|c|c|c|c|c|c|}
\hline \multicolumn{7}{|c|}{ WHOQOL-BREF } & \multicolumn{8}{|c|}{ SF-36 } \\
\hline Name & G1 & G4 & Phy & Psy & Soc & Env & $\mathrm{PF}$ & $\mathrm{RP}$ & $\mathrm{BP}$ & $\mathrm{GH}$ & VT & SF & $\mathrm{RE}$ & MH \\
\hline G1 & 1.00 & & & & & & & & & & & & & \\
\hline G4 & 0.59 & 1.00 & & & & & & & & & & & & \\
\hline Phy & 0.56 & 0.59 & 1.00 & & & & & & & & & & & \\
\hline Psy & 0.60 & 0.58 & 0.70 & 1.00 & & & & & & & & & & \\
\hline Soc & 0.50 & 0.51 & 0.61 & 0.73 & 1.00 & & & & & & & & & \\
\hline Env & 0.60 & 0.52 & 0.72 & 0.76 & 0.71 & 1.00 & & & & & & & & \\
\hline $\mathrm{PF}$ & 0.15 & 0.24 & 0.51 & 0.32 & 0.35 & 0.33 & 1.00 & & & & & & & \\
\hline $\mathrm{RP}$ & 0.33 & 0.38 & 0.50 & 0.42 & 0.42 & 0.40 & 0.54 & 1.00 & & & & & & \\
\hline BP & 0.42 & 0.39 & 0.53 & 0.39 & 0.33 & 0.43 & 0.49 & 0.51 & 1.00 & & & & & \\
\hline GH & 0.44 & 0.64 & 0.68 & 0.61 & 0.53 & 0.52 & 0.43 & 0.51 & 0.49 & 1.00 & & & & \\
\hline VT & 0.51 & 0.59 & 0.68 & 0.68 & 0.54 & 0.61 & 0.37 & 0.51 & 0.45 & 0.68 & 1.00 & & & \\
\hline SF & 0.49 & 0.50 & 0.63 & 0.58 & 0.54 & 0.55 & 0.46 & 0.61 & 0.66 & 0.61 & 0.61 & 1.00 & & \\
\hline RE & 0.44 & 0.45 & 0.55 & 0.49 & 0.42 & 0.50 & 0.40 & 0.71 & 0.48 & 0.50 & 0.54 & 0.60 & 1.00 & \\
\hline MH & 0.55 & 0.50 & 0.59 & 0.75 & 0.61 & 0.58 & 0.27 & 0.40 & 0.40 & 0.60 & 0.72 & 0.63 & 0.48 & 1.00 \\
\hline PCS & 0.21 & 0.28 & 0.48 & 0.26 & 0.30 & 0.32 & 0.84 & 0.78 & 0.72 & 0.46 & 0.30 & 0.56 & 0.56 & 0.15 \\
\hline MCS & 0.58 & 0.60 & 0.64 & 0.75 & 0.60 & 0.62 & 0.15 & 0.38 & 0.39 & 0.71 & 0.86 & 0.70 & 0.56 & 0.91 \\
\hline
\end{tabular}

Phy $=$ physical domain, $\quad$ Psy $=$ psychological domain, $\quad$ Soc $=$ social domain, Env $=$ environment domain, $P F=$ physical functioning, $\mathrm{RP}=$ role physical, $\mathrm{BP}=$ bodily pain, $\mathrm{GH}=$ general health perceptions, $\mathrm{VT}=$ vitality, $\mathrm{SF}=$ social functioning, $\mathrm{RE}=$ role emotional, $\mathrm{MH}=$ mental health, $\mathrm{PCS}=$ physical component summary, $\mathrm{MCS}=$ mental component summary.

Note: All $p$ value $<0.0001$.

ciation $(r$ range $=0.40-0.75)$. The highest correlation was found for the WHOQOL-BREF psychological domain and the SF-36 MH $(r=0.75)$. The correlations between the physical, psychological, and social domains (the WHOQOL-BREF) and $\mathrm{PF}, \mathrm{MH}$, and SF (the SF-36) were $0.51,0.75$, and 0.54 , respectively. This supports the first hypothesis that the corresponding domain/scale of both instruments should be positively correlated.

Regarding the two summary measures of the SF-36, the physical domain (the WHOQOLBREF) only has moderate association with PCS $(r=0.48)$, and all four domains of the WHOQOLBREF have strong associations with MCS $(r$ range $=0.60-0.75)$. Strong associations were also found between PF, RP, BP and PCS $(r$ range $=0.72-0.84)$ and between $\mathrm{MH}, \mathrm{RE}, \mathrm{SF}$ and MCS (range $=0.56-0.91$ ). The weak associations were found between psychological, social, and environment domain of the WHOQOL and PCS of the SF-36 ( $r$ range $=0.26-0.32)$. This partially supports the second hypothesis that the physical and psychological domains (the WHOQOLBREF) should have weak associations with MCS and PCS (the SF-36), respectively. Overall, the results of validity examination showed that both instruments have good convergent and discriminant validity.

Concurrent validity. All WHOQOL-BREF domains were substantially correlated with the measure of happiness $(r$ range $=0.64-0.76)$, the Sat-HRQOL $(r$ range $=0.66-0.70)$, and were moderately correlated with self-perceived health status $(r$ range $=0.46-0.62$, all $p<0.0001)$. All but one SF-36 scales were moderately to substantially associated with the measure of happiness $(r$ range $=0.40-0.69)$ with the exception of $\mathrm{PF}$ $(r=0.32)$. All of the SF-36 scales were moderately to substantially associate with the Sat-HRQOL $(r$ range $=0.40-0.63$ ), and self-perceived health status $(r$ range $=0.45-0.75$, all $p<0.0001)$. The highest association was found between $\mathrm{GH}$, the SF-36 and self-perceived health status $(r=0.75)$. PCS showed weak associations with the measure of happiness and Sat-HRQOL $(r=0.24,0.39$, respectively) but modest association with self-perceived health status $(r=0.46)$. Strong associations were evident between MCS and the measure of happiness, Sat-HRQOL, and self-perceived health status $(r=0.77,0.64,0.64$, respectively). All WHOQOL-BREF domains and SF-36 scales were negatively correlated with the number of symptoms 
$(r$ range $=-0.41$ to $-0.58,-0.46$ to -0.60 , respectively, all $p<0.0001)$ and intensity of symptoms $(r$ range $=-0.44$ to $-0.65,-0.50$ to -0.64 , respectively, all $p<0.0001)$. These results support the third and the fourth hypotheses and indicate good concurrent validity of both instruments.

Known-groups validity. Table 5 shows that, in general, HIV-infected patients with higher CD4 cell counts scored significantly higher on G4 (general health), three WHOQOL-BREF domains, seven SF-36 scales, and PCS (all $p<0.05$ ). The exceptions are G1 (overall QOL), the environment domain (the WHOQOL-BREF) and MH (the SF36). Patients with fewer symptoms and with less intensity of symptoms had significantly higher scores on all four domains of WHOQOL-BREF, eight scales, PCS, and MCS of the SF-36 scale (all $p<0.0001$, see Table 5). This supports the fifth hypothesis and indicates good known-groups validity of both instruments.

\section{Discussion}

The results of this study found that both the WHOQOL-BREF and the SF-36 had good reliability and validity among patients with HIV infection. The Cronbach's $\alpha$ values of WHOQOLBREF domains and SF-36 scales were generally good and comparable to results of previous studies [27-33]. Internal consistency reliability estimates for each domain/scale exceeded 0.70 , supporting the usefulness of both instruments in statistical analyses involving group comparison. The negatively skewed score distributions of the WHOQOLBREF and the SF-36 indicate more subjects scoring among the more favorable state. This is also an indication of validity, given that the majority of the subjects have high CD4 cell count and low intensity of symptoms. Noteworthy flooring and ceiling effects were observed for the two role-disability scales, consistent with what have been found in previous studies [34, 40]. These two scales are the coarsest of the SF-36 scales and are more susceptible to floor and ceiling effects than any of the other six scales [41]. However, all domains of WHOQOL did not show any of such effects.

Correlations between the scores of corresponding domains/scales between the WHOQOL-BREF and SF-36 were as hypothesized. The strong asso-

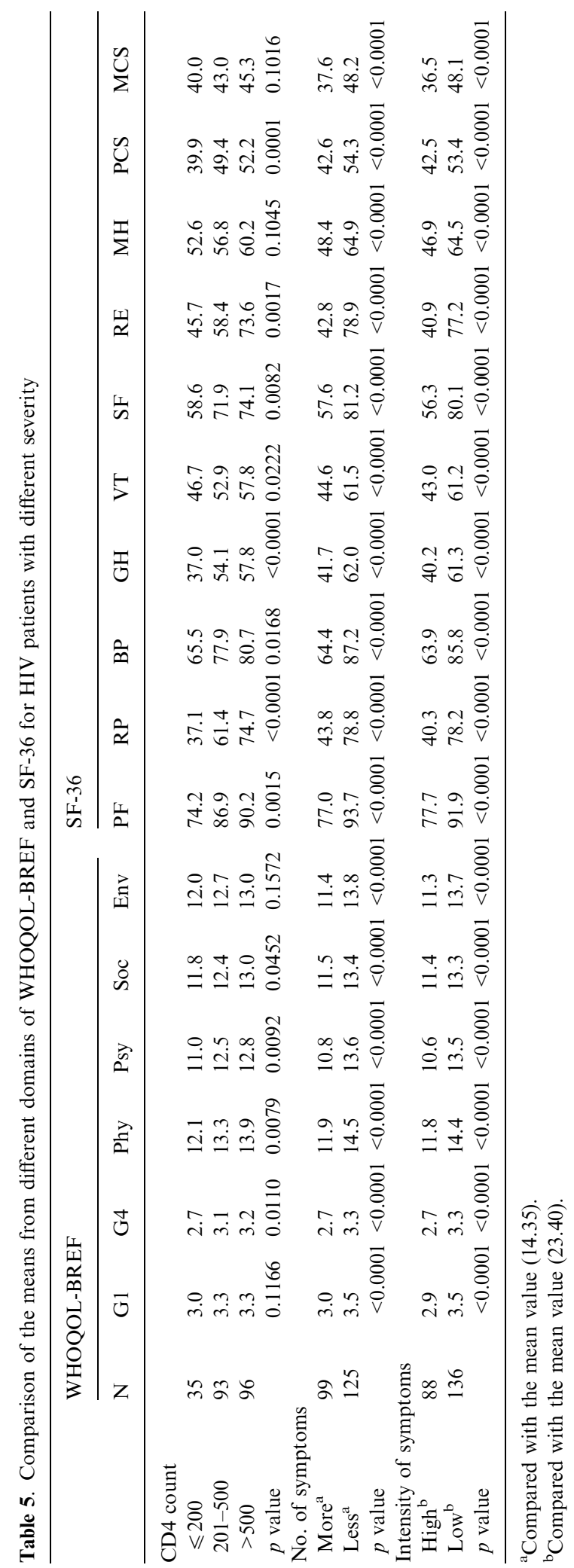


ciations between all four domains of the WHOQOL-BREF with MCS of the SF-36 might reflect the strong mental health component in the WHOQOL-BREF domains. The high correlations among the four domains also direct further exploration of the construct of the WHOQOL-BREF. As indicated in previous studies, PF, RP, BP correlate most highly with PCS, and MH, RE and SF correlate highly with MCS. Correlations between SF-36 scales and the PCS and MCS support the two-dimensional model of physical and mental health $[40,42]$. Although there were good correlations found in the scores of corresponding domains/scales between the WHOQOL-BREF and SF-36, there are also important differences between these two instruments. For example, items in PF of the SF-36 cover a range of clearly specified mild to vigorous physical activities in comparison with a variety of aspects (e.g. pain, energy, sleep, mobility) in the physical domain of the WHOQOL-BREF (see Appendix). Also, the content of the WHOQOL-BREF social domain encompasses a larger scope (e.g. personal relationships, social support, sexual activity) than that of the SF-36 social functioning (i.e. social activities) or role functioning (i.e. work/daily activities) scales. As indicated in the literature, the SF-36 was originally developed as an instrument for health survey. Subsequently, it was widely used in studies of health-related QOL and MOS. Therefore, it is reasonable that the items in the SF-36 reflect more toward the scope of health status. The aim of WHOQOL-BREF was to capture a broad-ranging concept of QOL to the extent of incorporating environment domain in its scope.

The scores of all the WHOQOL-BREF domains and all the SF-36 scales were consistently positively correlated with the measure of happiness, SatHRQOL, and self-perceived health status, and negatively correlated with the number and intensity of symptoms. While the association between the PCS and the measure of happiness was found to be weak, the association between the MCS and the measure of happiness was found to be strong. It suggests that mental health component is more aligned with the concept of happiness. Furthermore, there was a consistent trend of increasing scores of the WHOQOL-BREF and SF-36 along with increasing levels of CD4 lymphocyte counts. Specifically, the differential capacity of several domains/scales implies the usefulness of both instruments in future outcome studies. Because disease-specific QOL instruments, such as the MOS-HIV [17], did not allow for cross-disease comparison, the above findings suggest that both the WHOQOL-BREF and the SF-36, although regarded as generic health-related QOL instruments, could be quite useful for HIV-infected patients to be compared with other diseases or conditions and for cost-effectiveness and economic analysis.

Some limitations of this study should be addressed. First, highly active antiretroviral therapy was freely available to all HIV-infected citizens through the Taiwan National Health Insurance program. The majority of HIV-infected patients enrolled in this study was receiving highly active antiretroviral therapy and strived to lead an active life. Thus, the results may not be directly generated to many HIV-infected patients for whom lack of accessibility to effective antiretroviral therapy is a cruel reality. Second, the majority of patients enrolled in this study were outpatients. The study was unable to enroll a large number of inpatients because these patients were often too ill to be able to adequately respond to the questionnaires. Third, this study used a cross-sectional design. Future longitudinal studies are needed to determine the responsiveness of these two QOL instruments to changes in the clinical status of patients with HIV infection.

In conclusion, both the WHOQOL-BREF and SF-36, two generic health-related QOL instruments, are useful for assessing QOL in patients with HIV infection. And, in general, there are good correlations between the corresponding domains/scales of the two instruments.

\section{Acknowledgements}

This study was supported by grants DOH-90-DC1049, DOH-91-1056 from the Department of Health, Executive Yuan, Taiwan, and NHRIEX92-9204PP from National Health Research Institutes, Taiwan. We would like to thank Dr. Shiow-Ing $\mathrm{Wu}$, the Taipei Municipal Venereal Disease Control Institute, and National Taiwan University Hospital for allowing us to enroll their patients. We also thank the Garden of Mercy Foundation's referral of subjects. We are most grateful to all the subjects of this study for their valuable participation. 


\section{Appendix:}

Correlations of item and its domain of the WHOQOL-BREF

\begin{tabular}{|c|c|c|c|}
\hline Domains & Item no. & Item abbreviation & Correlation \\
\hline & $1(\mathrm{G} 1)$ & Overall QOL & \\
\hline & $2(\mathrm{G} 4)$ & General health & \\
\hline \multirow[t]{7}{*}{ Physical } & 3 & Pain and discomfort & 0.61 \\
\hline & 10 & Energy and fatigue & 0.73 \\
\hline & 16 & Sleep and rest & 0.73 \\
\hline & 15 & Mobility & 0.72 \\
\hline & 17 & Activities of daily living & 0.79 \\
\hline & 4 & Dependence of medical substances/aids & 0.55 \\
\hline & 18 & Work capacity & 0.68 \\
\hline \multirow[t]{6}{*}{ Psychological } & 5 & Positive feelings & 0.76 \\
\hline & 7 & Thinking, learning, memory, concentration & 0.76 \\
\hline & 19 & Self-esteem & 0.81 \\
\hline & 11 & Bodily image and appearance & 0.69 \\
\hline & 26 & Negative feelings & 0.65 \\
\hline & 6 & Spirituality/religion/personal beliefs & 0.85 \\
\hline \multirow[t]{4}{*}{ Social } & 20 & Personal relationships & 0.82 \\
\hline & 22 & Practical social support & 0.78 \\
\hline & 21 & Sexual activity & 0.70 \\
\hline & 27 & Being respected/accepted & 0.72 \\
\hline \multirow[t]{9}{*}{ Environment } & 8 & Freedom, physical safety, and security & 0.71 \\
\hline & 23 & Home environment & 0.70 \\
\hline & 12 & Financial resources & 0.69 \\
\hline & 24 & Health and social care: accessibility and quality & 0.64 \\
\hline & 13 & Opportunities for acquiring new info. and skills & 0.74 \\
\hline & 14 & Participation in and opportunities for recreation/leisure activities & 0.73 \\
\hline & 9 & Physical environment (pollution/noise/traffic/climate) & 0.58 \\
\hline & 25 & Transport & 0.72 \\
\hline & 28 & Eating/food & 0.67 \\
\hline
\end{tabular}

\section{References}

1. Palella FJ, Delaney KM, Moorman AC, Loveless MO, Fuhrer J, Satten GA, Aschman DJ, Holmberg SD. Declining morbidity and mortality among patients with advanced human immunodeficiency virus infection. N Engl J Med 1998; 338: 853-860.

2. Wu AW. Quality of life assessment comes of age in the era of highly active antiretroviral therapy. AIDS 2000; 14: 1449-1451.

3. Hays RD, Cunningham WE, Sherbourne CD, et al. Healthrelated quality of life in patients with human immunodeficiency virus infection in the United States: Results from the HIV Cost and Services Utilization Study. Am J Med 2000; 108: 714-722.

4. Cunningham WE, Shapiro MF, Hays RD, et al. Constitutional symptoms and health-related quality of life in patients with symptomatic HIV disease. Am J Med 1998; 104: 129-136.

5. Lorenz KA, Shapiro MF, Asch SM, Bozzette SA, Hays RD. Associations of symptoms and health-related quality of life: Findings from a national study of persons with HIV infection. Ann Int Med 2001; 134: 854-860.

6. Bing EG, Hays RD, Jacobson LP, et al. Health-related quality of life among people with HIV disease: Results from the Multicenter AIDS Cohort Study. Qual Life Res 2000; 9: $55-63$.

7. Low-Beer S, Chan K, Wood E, et al. Health-related quality of life among persons with HIV after the use of protease inhibitors. Qual Life Res 2000; 9: 941-949.

8. Osowiecki DM, Cohen RA, Morrow KM, et al. Neurocognitive and psychological contributions to quality of life in HIV-1-infected women. AIDS 2000; 14: 1327-1332.

9. Weinfurt KP, Willke RJ, Glick HA, Freimuth WW, Schulman KA. Relationship between CD4 count, viral burden, and quality of life over time in HIV-1-infected patients. Med Care 2000; 38: 404-410.

10. Nieuwkerk PT, Gisolf EH, Colebunders R, Wu AW, Danner SA, Sprangers MA. Quality of life in asymptomatic and symptomatic HIV-infected patients in a trial of ritonavir/saquinavir therapy. The Prometheus Study Group. AIDS 2000; 14: 181-187.

11. Nieuwkerk PT, Gisolf EH, Reijers MH, Lange JM, Danner SA, Sprangers MA. Long-term quality of life outcomes in three antiretroviral treatment strategies for HIV-1 infection. AIDS 2001; 15: 1985-1991.

12. Bucciardini R, Wu AW, Floridia M, et al. Quality of life outcomes of combination zidovudine-didanosine-nevirapine and zidovudine-didanosine for antiretroviral-naive advanced HIV-infected patients. AIDS 2000; 14: 2567-2574. 
13. Freedberg KA, Losina E, Weinstein MC, et al. The cost effectiveness of combination antiretroviral therapy for HIV disease. N Engl J Med 2001; 344: 824-831.

14. Schackman BR, Goldie SJ, Weinstein MC, Losina E, Zhang H, Freedberg KA. Cost-effectiveness of earlier initiation of antiretroviral therapy for uninsured HIV-infected adults. Am J Public Health 2001; 91: 1456-1463.

15. Smith MY, Feldman J, Kelly P, DeHovitz JA, Chirgwin K, Minkoff H. Health-related quality of life of HIV-infected women: Evidence for the reliability, validity and responsiveness of the Medical Outcomes Study Short-Form 20. Qual Life Res 1996; 5: 47-55.

16. Wachtel T, Piette J, Mor V, Stein M, Fleishman J, Carpenter C. Quality of life in persons with human immunodeficiency virus infection: Measurement by the Medical Outcomes Study instrument. Ann Int Med 1992; 116: 129-137.

17. Wu AW, Revicki DA, Jacobson D, Malitz FE. Evidence for reliability, validity and usefulness of the Medical Outcomes Study HIV Health Survey (MOS-HIV). Qual Life Res 1997; 6: 481-493.

18. Call SA, Klapow JC, Stewart KE, et al. Health-related quality of life and virologic outcomes in an HIV clinic. Qual Life Res 2000; 9: 977-985.

19. Kaplan RM, Anderson JP, Patterson TL, et al. Validity of the Quality of Well-Being Scale for persons with human immunodeficiency virus infection. Psychosom Med 1995; 57: $138-147$

20. Leplege A, Rude N, Ecosse E, Ceinos R, Dohin E, Pouchot J. Measuring quality of life from the point of view of HIVpositive subjects: the HIV-QL31. Qual Life Res 1997; 6: 585-594.

21. Holmes WC, Shea JA. A new HIV/AIDS-targeted quality of life (HAT-QoL) instrument: Development, reliability, and validity. Medical Care 1998; 36: 138-154.

22. Lubeck DP, Fries JF. Assessment of quality of life in early stage HIV-infected persons: Data from the AIDS Timeoriented Health Outcome Study (ATHOS). Qual Life Res 1997; 6: 494-506.

23. De Boer JB, Sprangers MA, Aaronson NK, Lange JM, van Dam FS. A study of the reliability, validity and responsiveness of the HIV overview of problems evaluation system (HOPES) in assessing the quality of life of patients with AIDS and symptomatic HIV infection. Qual Life Res 1996; 5: 339-347.

24. Smith KW, Avis NE, Mayer KH, Swislow L. Use of the MQoL-HIV with asymptomatic HIV-positive patients. Qual Life Res 1997; 6: 555-560.

25. Peterman AH, Cella D, Mo F, McCain N. Psychometric validation of the revised Functional Assessment of Human Immunodeficiency Virus Infection (FAHI) quality of life instrument. Qual Life Res 1997; 6: 572-584.

26. Fang CT, Hsiung PC, Yu CF, Chen MY, Wang JD. Validation of the World Health Organization Quality of Life instrument in patients with HIV infection. Qual Life Res 2002; 11: 753-762.

27. WHOQOL Group. The World Health Organization quality of life assessment (WHOQOL): Development and general psychometric properties. Soc Sci Med 1998; 46: 1569-1585.

28. WHOQOL Group. The development of the World Health Organization Quality of Life Assessment Instrument (the
WHOQOL). In: Orley J, Kuyken W (eds), Quality of Life Assessment: International Perspectives, New York: Springer-Verlag, 1994.

29. WHOQOL Group. Development of the World Health Organization WHOQOL- BREF quality of life assessment. Psychol Med 1998; 28: 551-558.

30. Yao G, Chung CW, Yu CF, Wang JD. Development and verification of validity and reliability of the WHOQOL-BREF Taiwan version. J Formos Med Assoc 2002; 101: 342-351.

31. Ware JE, Snow KK, Kosinski M. SF-36 Health Survey: Manual and Interpretation Guide. Lincoln, RI: QualityMetric Incorporated, 1993, 2000.

32. McHorney CA, Ware JE, Lu JFR, Sherbourne CD. The MOS 36-item short-form health survey (SF-36): III. Tests of data quality, scaling assumptions, and reliability across diverse patient groups. Med Care 1994; 32: 40-66.

33. Thumboo J, Fong KY, Ng TP, et al. Validation of the MOS SF-36 for quality of life assessment of patients with systemic lupus erythematosus in Singapore. J Rheumatol 1999; 26: 97-102.

34. Ware JE, Keller SD, Gandek B, Brazier JE, Sullivan M. The IQOLA Project Group. Evaluating translations of health status questionnaires: Methods from the IQOLA project. Int J Technol Assess Health Care 1995; 11: 525-551.

35. McHorney CA, Ware JE, Raczek AE. The MOS 36-item short-form health survey (SF-36): II. Psychometrics and clinical testes of validity in measuring physical and mental health constructs. Med Care 1993; 31: 247-263.

36. Ware JE, Kosinski M, Bayliss MS, McHorney CA, Rogers WH, Raczek AE. Comparison of methods for the scoring and statistical analysis of SF-36 health profiles and summary measures: Summary of results from the Medical Outcomes Study. Med Care 1995; 33 (Suppl. 4): AS264-AS279.

37. Lin CH. Scale Validation and Norm Establishing of the SF36 Taiwan Version. Unpublished Master Thesis. Taichung: China Medical University, 2003.

38. Holzemer WL, Henry SB, Nokes KM, et al. Validation of the sign and symptom check-list for persons living with HIV disease (SSC-HIV). J Adv Nurs 1999; 30: 1041-1049.

39. Tsai YF, Hsiung PC, Holzemer WL. Validation of a Chinese version of the sign and symptom checklist for persons with HIV diseases (SSC-HIV-C). J Pain Symptom Manage 2003; 25: 363-368.

40. Ware JE, Kosinski M, Keller SD. SF-36 Physical and Mental Health Summary Scales: A User's Manual. Boston: The Health Institute, 1994.

41. Ware JE. SF-36 health survey update. Spine 2000; 25: 3130 3139.

42. Kosinski M, Keller SD, Hatoum HT, Kong SX, Ware JE. The SF-36 health survey as a generic outcome measure in clinical trials of patients with osteoarthritis and rheumatoid arthritis: Tests of data quality, scaling assumptions and score reliability. Med Care 1999; 37: MS10-MS22.

Address for correspondence: Jung-Der Wang, College of Public Health, National Taiwan University, Tapei 100, Taiwan Phone: + 886-2-23516561; Fax: + 886-2-23911308

E-mail: jdwang@ha.mc.ntu.edu.tw 